\title{
The Experimental Investigation and Nonlinear Regression Analysis of the Effect of Tire Inflation Pressure on Pitch Force
}

\author{
Hüseyin Bayrakçeken ${ }^{1}$, Zekeriya Girgin ${ }^{2}$, Faruk Emre Aysal ${ }^{1}$, Mustafa Babagiray ${ }^{1 *}$ \\ 0000-0002-1572-4859, 0000-0001-5958-9735, 0000-0002-9514-1425, 0000-0002-2482 \\ ${ }^{1}$ Automotive Engineering Department, Faculty of Technology, Afyon Kocatepe University, Afyonkarahisar, 03200, Turkey \\ ${ }^{2}$ Mechanical Engineering Department, Faculty of Engineering, Pamukkale University, Denizli, 20070, Turkey
}

\section{Abstract}

In this study, the effect of tire inflation pressure on the vehicle during braking was investigated experimentally. The experimental study was carried out in the Brake-Suspension Test Device designed as a half-vehicle model, which enables vehicle brake tests to be performed in the laboratory. During the tests, a total of nine different tire inflation pressures from 26 psi to 40 psi standard value were taken into consideration. As a result of the experiments carried out separately for each tire inflation pressure, a curve characterizing the effect of different pressure values on the pitching force was obtained. Based on the experimental results, different mathematical models suitable for the curve obtained are derived by nonlinear curve fitting. For the nonlinear curve fitting process, a hybrid iterative regression algorithm obtained by combining classical curve fitting algorithm with Newton-Raphson iteration method was used. It was observed that the correlation coefficients (R2) of the mathematical models obtained provided sufficient sensitivity to express the problem under consideration.

Keywords: Nonlinear Curve Fitting, Pitching Force, Tire Inflation Pressure, Vehicle Dynamics
Research Article

https://doi.org/10.30939/ijastech..794873

Received $\quad 14.09 .2020$

Revised 19.11 .2020

Accepted 25.11.2020

* Corresponding author

Mustafa Babagiray

mbabagiray@aku.edu.tr

Address: Automotive Engineering Department, Faculty of Technology, Afyon Kocatepe University, Afyonkarahisar, Turkey

Tel:+902722182543

\section{Introduction}

As a result of the rapid developments from the 19th century until today, vehicles have become indispensable elements of daily life. Especially in the 90's and later, researchers focused on improving fuel economy in vehicles, reducing exhaust emissions, and improving vehicle comfort and safety. This situation led to a similar orientation of academic studies in the automotive field. For this purpose, studies have been carried out in many areas such as alternative fuels, different transmission systems and control methods, different suspension systems, and different tire types. Along with these studies, tire inflation pressure is one of the most important factors affecting fuel economy, driving comfort and safety [1].

When the literature is reviewed, it is seen that many studies have been conducted on the effects of tire inflation pressure on the vehicle. Various tire inflation pressure control systems have been developed by researchers to reduce fuel consumption. However, the effect of tire inflation pressure change on fuel economy has been experimentally investigated in different studies [2]. Rieter and Wagner (2010) examined the effect of low tire inflation pressure on vehicle steering in order to increase driving quality and safety while driving. The results show that the lower front wheel pressure causes the turning angle to increase. They observed that if the rear wheel pressure is large, the angle of skid increases. Koca (2007) examined the dynamic wheel radius at different tire inflation pressures and different vehicle speeds at three tires with different load and speed characteristics. It was found that the wheel dynamic radius increased due to the speed increase and tire pressure change, and the dynamic radius increased significantly after $60 \mathrm{~km} / \mathrm{h}$ vehicle speed [3]. Sina et al. (2015) studied the effect of different tire pressures on tire power losses under real road conditions. They observed that at $22 \mathrm{psi}$ at positive inclination, the least power loss occurred in the drive wheels, while rolling resistance increased by $12 \%$. In negative slope, they observed that the minimum power loss and rolling resistance were at 36 psi in the drive wheels [4]. Cuong et al. (2013) examined the effect of tire pressure on vibration in a tractor without suspension. During the experiments, they measured the lateral vibration accelerations of the front and rear axles and the triaxial vibration acceleration of the tractor body using an accelerometer. As a result of the experiments, they concluded that speed and tire pressure significantly affect vibration [5]. Karakuş and Çolakoğlu (2008) determined the 2-dimensional and 3-dimensional modeling of a 175/70 / R13 car tire by the stresses occurring at different internal pressures of the tire. They observed 
that the maximum stress was on the sidewall of the tire and on the inner surface of the carcass, and the tension increased almost directly depending on the internal pressure [6]. Bayrakçeken et al. (2019) experimentally examined the effect of tire inflation pressure, which is lower than the rated pressure, on the vehicle, in particular the pitching force. In addition, as a result of the study, the relationship between low tire inflation pressure and pitching force of the vehicle was modeled by curve fitting method with two different functions [7].

This study aims to reveal the effect of the tire inflation pressure above and below the rated pressure (34 psi) on the pitching force that occurs during braking. In the brake tests performed for this purpose, a total of nine different tire inflation pressure tests from 24 psi to 40 psi were carried out. Based on the experimental results, different equations suitable for the curve obtained were derived using the Hybrid Iterative Curve Fitting Algorithm. As a result, the relationship between tire inflation pressure and pitch force is expressed by mathematical models with high correlation coefficients.

\section{Materials and Methods}

\subsection{Experimental study}

In addition to the steering wheel control, the brake force also plays an active role in keeping a moving vehicle under control. An effective braking force is the result of good braking performance. Brake performance is basically measured based on stopping distance, brake output torque or brake efficiency. Tests to evaluate the brake performance are performed on the brake tester or vehicle by changing parameters such as load, speed, temperature, pedal force/brake pressure and tire air pressure.

Drum type electromechanical brake test devices are widely used for brake force measurement in the determination of vehicle brake forces. In these devices, the values are determined by the wheels of the vehicle rising on the drums of the brake device and by applying the brakes while the rollers are turning the wheels. Apart from this, flat floor test platforms are also used to measure vehicle brake force. In the brake test with flat ground test platforms, the vehicle is dragged on the platform at a speed of about $8 \mathrm{~km} / \mathrm{h}$ and braked hard. However, such test devices cannot provide the sensitivity and conditions suitable for academic studies. For this reason, various test devices have been developed for researchers to perform brake tests precisely in the laboratory environment. Brake Suspension Test Device, one of these devices, was used in the experimental part of this study [8].

Table 1. Features of the Tester

\begin{tabular}{c|c}
\hline Internal-combustion engine & 4 Cylinder, Gasoline Engine \\
\hline Engine capacity & $1,4 \mathrm{~L}$ \\
\hline Engine Maximum Power & $57 \mathrm{~kW}$ \\
\hline Engine Maximum Torque & $115 \mathrm{Nm}$ \\
\hline Tire Information & $175 / 70 \mathrm{R} 14$ \\
\hline
\end{tabular}

In the experiment, the ambient temperature was determined as $25^{\circ} \mathrm{C}$. The experiments were carried out using the brake-suspen- sion test device given in Figure 1. Engine features used in the device are given in Table 1.

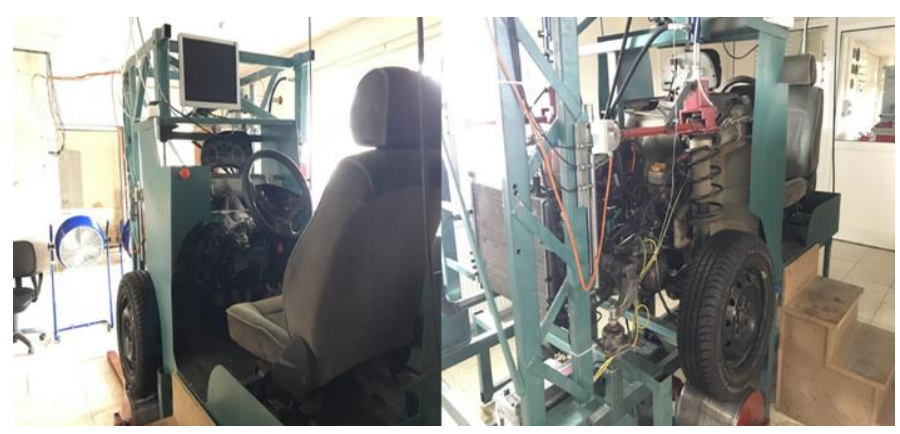

Fig. 1. Brake suspension tester

The brake suspension tester in Figure 1 basically measures the pitching force coming to the suspension wedge during braking. Experiments were carried out by braking every 20 seconds at 3000 rpm in the 3rd gear for 300 seconds for each tire inflation pressure.

\subsection{Non-linear iterative regression}

Regression analysis was developed and put forward by legendre, Gauss, Galton and Fisher in the 19th and 20th centuries. Regression analysis is used for curve fitting purposes in most of the current studies. Thus, numerical modeling of events that are difficult to model analytically is provided in the light of experimental data[9,10-14]. In this study, numerical modeling has been done by using the Hybrid method whose algorithm is given in Equation (1), (2) and (3). The method consists of a combination of nonlinear regression algorithm and Newton-Raphson iteration method.

$$
\begin{aligned}
& f(i)=a 1 \cdot x(i)^{2}+a 2 \cdot x(i)+a 3-y(i) \\
& h(i, j)=\sum_{j=1}^{k} \frac{\partial f(i)}{\partial a_{k}} \\
& a_{k}=a_{k}-\frac{f(i)}{h(i, j)}
\end{aligned}
$$

Here, Eq. (1) represents the sample model. Classical nonlinear regression formulation is given in Equation 2, and NewtonRaphson expression giving model coefficients is given in Eq. (3). When the coefficients obtained by using the hybrid algorithm are used, the target mathematical model given in Eq. (1) is written as presented in Eq. (4).

$y(x)=a 1 \cdot x^{2}+a 2 \cdot x+a 3$

Empirical relations derived by curve fitting and similar methods based on experimental data have certain margins of error in the extent of the accepted acceptances and approaches. The correlation constant $\mathrm{R}^{2}$ given in Eq. (5) is used to determine the amount of error, especially in the modeling made with curve fitting [15].

$R^{2}=\frac{\sum\left(y_{\text {real }}-y_{\text {prediction }}\right)^{2}}{\sum\left(y_{\text {real }}-y_{\text {real mean }}\right)^{2}}$ 


\section{Results and Discussion}

In this study, in order to reveal the relationship between pitching force and tire inflation pressure, a total of nine different pressures from 24 psi to 40 psi rated pressure were performed. Ex- periments were carried out by applying braking every 20 seconds at $3000 \mathrm{rpm}$ for 300 seconds for each tire inflation pressure. Average pitching force was obtained for each tire inflation pressure by taking the average of the force values measured during the experiment. Table 2 shows the average pitching forces up to a tire inflation pressure of $24-40$ psi.

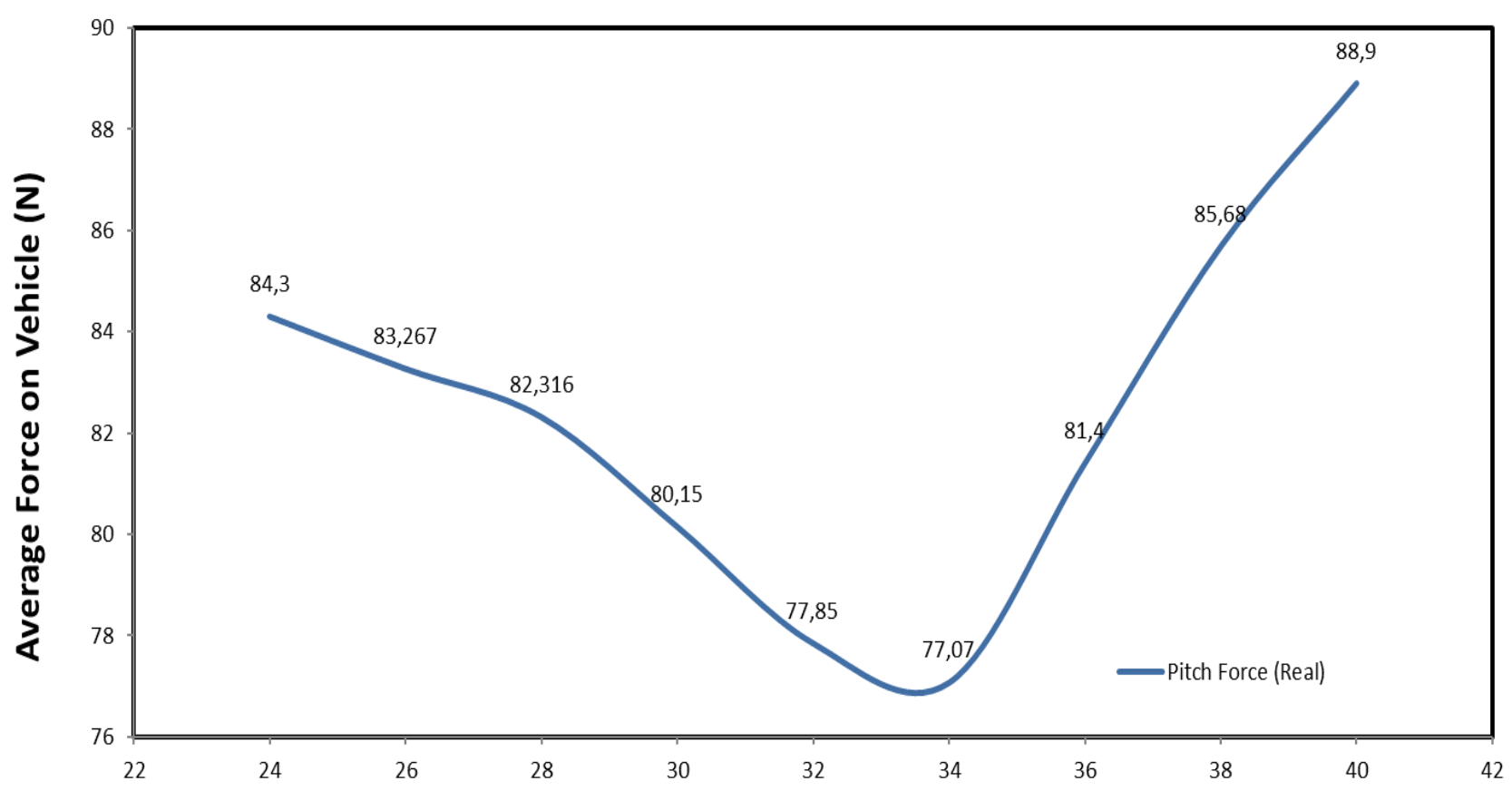

Tire Pressure (psi)

Fig. 2. Average pitch force to $24-40$ psi tire inflation pressure

Table 2. Average Pitch Force to 24 - 40 psi tire inflation pressure

\begin{tabular}{c|c|c}
$\begin{array}{c}\text { Tire Inflation Pres- } \\
\text { sure (psi) }\end{array}$ & $\begin{array}{c}\text { Average Pitch } \\
\text { Force (N) }\end{array}$ & $\begin{array}{c}\text { Brake Main Cen- } \\
\text { ter Pressure (bar) } \\
\text { During Braking }\end{array}$ \\
\hline 24 & 84.3 & \\
\hline 26 & 83.267 & \\
\hline 28 & 82.316 & \\
\hline 30 & 80.15 & \multirow{2}{*}{8} \\
\hline 32 & 77.85 & \\
\hline 34 & 77.07 & \\
\hline 36 & 81.4 & \\
\hline 38 & 85.68 & \\
\hline 40 & 88.9 & \\
\hline
\end{tabular}

The relationship between the pitching force generated in the suspension wedge during braking and the brake force can be expressed as given in Equation 6 at high inflation pressures where the vehicle tire behaves close to a rigid material. Here, the pitching force is shown by $\mathrm{F}_{\text {pitching }}$, the brake force $\mathrm{F}_{\text {brake }}$, the dynamic wheel radius $R_{\text {dyn }}$, the distance of the outer surface of the brake disc to the suspension wedge $\mathrm{L}_{\text {disc }}$ and the radius of the brake disc with $\mathrm{r}_{\text {disc. }}$.

$$
\begin{aligned}
& F_{\text {pitching }} \cdot\left(L_{\text {disc }}+r_{\text {disc }}\right)=F_{\text {brake }} \cdot R_{\text {dyn }} \\
& F_{\text {pitching }}=F_{\text {brake }} \frac{R_{\text {dyn }}}{\left(L_{\text {disc }}+r_{\text {disc }}\right)}
\end{aligned}
$$

Fig. 2 shows that average pitching forces up to 24 - 40 psi tire inflation pressure. As it can be seen from Eq. (7), as the tire inflation pressure increases, the dynamic wheel radius will increase and the pitching force generated during braking is expected to increase. However, at tire pressures less than 34 psi, the pitch force increased rather than decreased. Tire, which is a polymer material, can show reactions such as adhesion and adhesion to the contact surface at sub-standard tire inflation pressures. Adhesion between the tire and surface is increase in low tire pressure values. Additionally, the inertia of the test device is same at each tire pressure. Therefore, the adhesion increased by low tire pressure could be lead to increasing in term of pitch force during the braking process. As a result, at tire inflation pressures below the rated pressure, the tire may have shown a nonlinear behavior contrary to Eq. (1). 


$$
\mathrm{R}^{2}=0.9967 \text {. }
$$

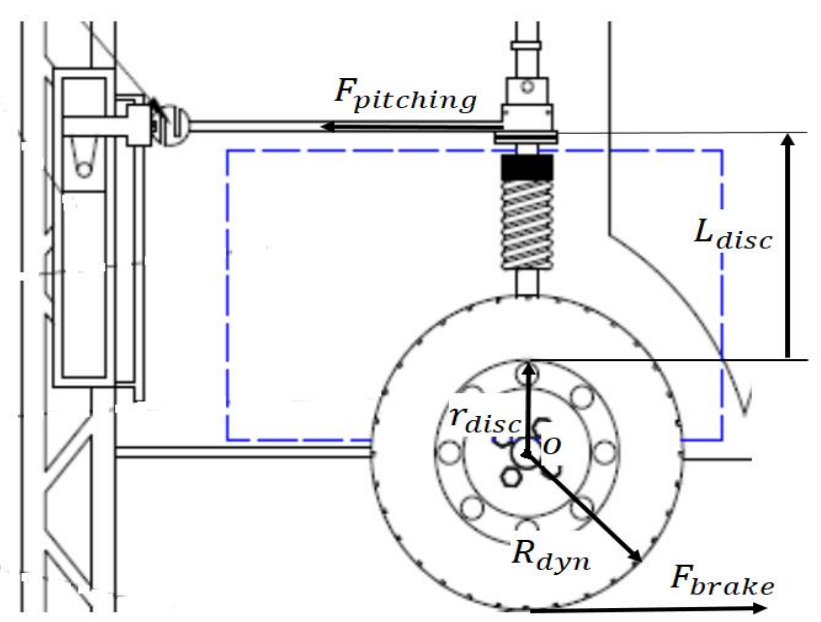

Fig. 3. Tester wheel group schematic

When the effect of tire inflation pressure on pitching force during braking was examined experimentally, a parabolic change was observed. However, considering the non-linear factors arising from vehicle dynamics, it is predicted that the relationship between tire inflation pressure and pitching force can be modeled by parabolic or periodic functions. Therefore, the periodic functions given in Eq. (8), (9) and (10) and the parabolic functions given in Eq. (11) and (12) are considered as models for curve fitting. The coefficients and R2 values of the functions derived by using the hybrid regression model, which is an iterative algorithm, as seen in Eq. (3), are given in Table 3.

$$
\begin{aligned}
& y(x)=a_{0}+\sum_{n=1}^{\infty}\left(a_{n} \cos \frac{n \pi x}{L}+b_{n} \sin \frac{n \pi x}{L}\right) \\
& y(x)=\sum_{j=1}^{n}\left(a_{j} \sin \left(b_{j} \cdot \mathrm{x}+c_{j}\right)\right)
\end{aligned}
$$

By using the hybrid regression method, the Fourier series given in Eq. (8) is expanded to the second terms and as a result of the curve fitting performed, a mathematical model that provides the sensitivity of $\mathrm{R}^{2}=0.9957$ is presented. When the Sine series expansion given in Eq. (9) is expanded to the third terms, a modeling with $\mathrm{R}^{2}=0.9931$ is provided in the curve fitting made using the model obtained.

The Gaussian series expansion, which is the last periodic model considered as the basis of the mathematical model, is given in Eq. (10). When the Gaussian series is expanded to its third terms, the regression using the function obtained has provided a sensitivity of

$$
y(x)=\sum_{j=1}^{n}\left(a_{j} \cdot e^{-\left(\frac{x-b_{j}}{c_{j}}\right)^{2}}\right)
$$

Figure 4 shows mathematical models derived from periodic functions. When the $\mathrm{R}^{2}$ values of the derived curve fittings were examined, it was seen that the periodic function expansions discussed could be used as a mathematical model for the relationship between tire inflation pressure and pitch force. However, since all three equations are periodic, a mathematical model can be obtained in only one period of the function, namely as "local". Therefore, two different parabolic functions given in Eq. (11) and (12) as an alternative to periodic functions are considered as mathematical models.

$$
\begin{gathered}
y(x)=\sum_{j=1}^{n}\left(a_{j} \cdot x^{j-1}\right) \\
(x)=\sum_{j=1}^{n}\left(a_{j} \cdot e^{b_{j}}\right)
\end{gathered}
$$

The general polynomial equation given in Eq. (11) is handled as a third order polynomial and a mathematical model with $\mathrm{R}^{2}=$ 0.9104 is derived as a result of the curve fitting. The last equation considered to model the relationship between tire inflation pressure and pitching force is the exponential function seen in Eq. (12). As a result of the modeling by expanding Equation 11 up to the second term, a curve fitting with a precision of $\mathrm{R}^{2}=0.8881$ is performed. Fig. 5 shows mathematical models derived from parabolic functions. It is seen that $R^{2}$ values of mathematical models obtained as a result of modeling based on parabolic functions are lower than periodic functions. However, it is seen that the models obtained as a result of curve fitting made with parabolic functions are more globally compatible with the physics of the problem. However, in third order polynomials, the function curve is similar to the combination of two parabolas. Therefore, it is seen that the modeling made with the third order polynomial does not exactly fit the physics of the problem, but it fits in one half of the function. The graph of the exponential function obtained as a result of the modeling based on Eq. (12) consists of a single parabola in accordance with the physics of the problem under consideration. Although R2 value is the lowest among the derived mathematical models, it is seen that the most suitable function to define the relationship between tire inflation pressure-pitching forces globally is the second order expansion of Eq. (12). 
Table 3. Equation coefficients obtained by hybrid regression

\begin{tabular}{c|c|c|c|c|c}
\hline & $\begin{array}{c}\mathbf{3}^{\text {rd }} \text { Degree } \\
\text { Polynominal }\end{array}$ & $\begin{array}{c}\mathbf{2}^{\text {nd }} \text { Order } \\
\text { Exponentinal }\end{array}$ & $\mathbf{2}^{\text {nd }}$ Order Fourier & $\begin{array}{c}\mathbf{3}^{\text {rd }} \text { Order } \\
\text { Gaussian }\end{array}$ & $\begin{array}{c}3^{\text {rd }} \text { Order Sine } \\
\text { Sum }\end{array}$ \\
\hline $\mathbf{R}^{\mathbf{2}}$ & 0.9104 & 0.8881 & 0.9957 & 0.9967 & 0.9931 \\
\hline $\mathbf{a} 0$ & - & - & 83.07 & - & - \\
\hline $\mathbf{a}_{1}$ & -76.82 & 132.8 & 4.903 & 89.25 & 173.2 \\
\hline $\mathbf{a} 2$ & 19.37 & 0.04152 & -0.2783 & 64.88 & 96.21 \\
\hline $\mathbf{a} 3$ & 0.7468 & - & - & 12.99 & 3.853 \\
\hline $\mathbf{a}$ & 0.009168 & - & - & - & - \\
\hline
\end{tabular}

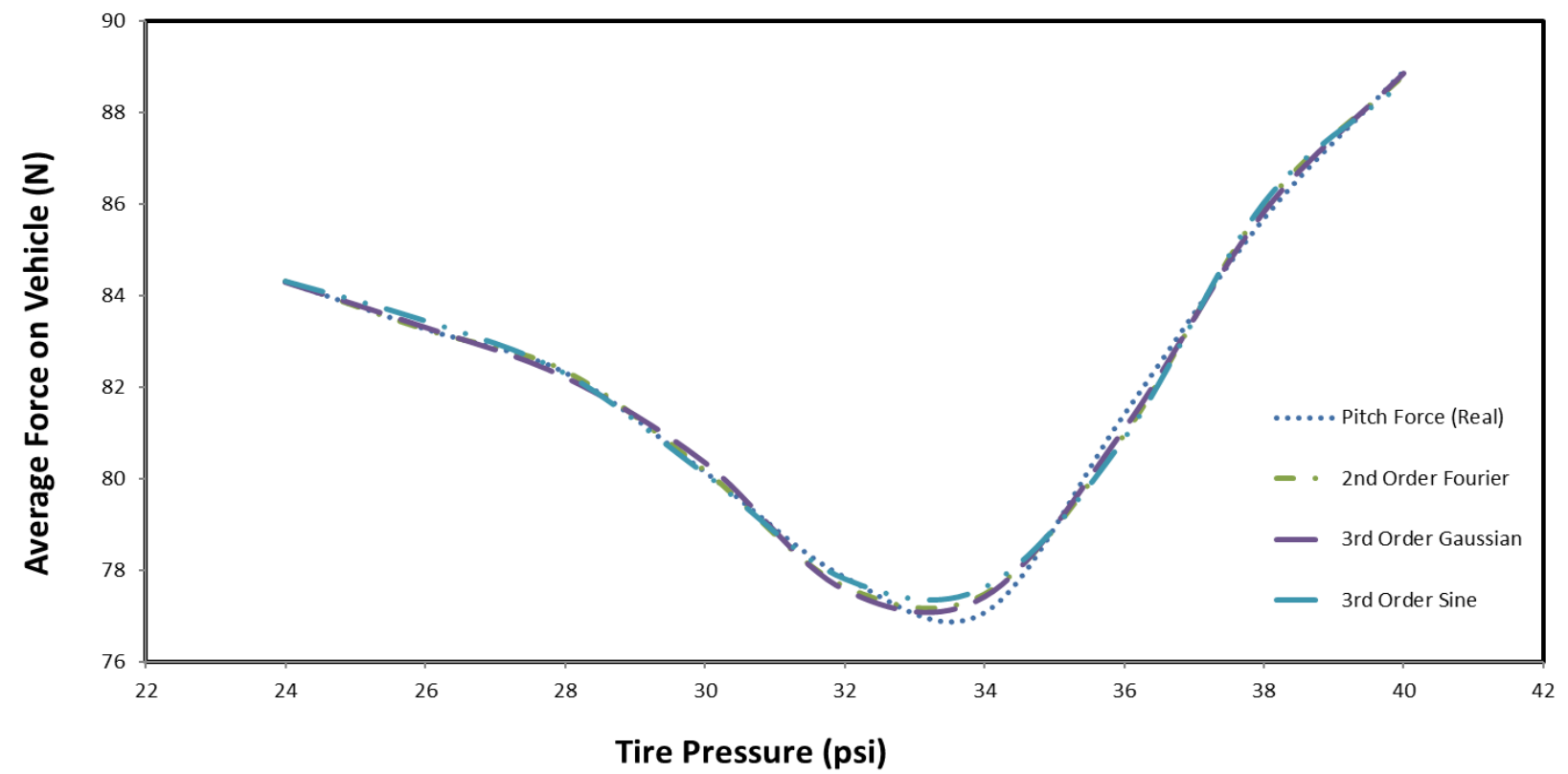

Fig. 4. Mathematical models derived with periodic functions

The $\mathrm{R}^{2}$ values of the functions derived using the Hybrid Iterative Regression model whose algorithm is given in Equation 1-3 showed that the algorithm can be successfully used in curve fitting studies of nonlinear problems. High $\mathrm{R}^{2}$ values obtained in curve fitting studies with periodic functions that present a local model to the problem in particular revealed that the Hybrid Iterative Regression algorithm is a reliable approach.

\section{Conclusion}

In this study, the pitching force generated in vehicle suspensions during braking was investigated. For this purpose, brake tests at different tire inflation pressures were carried out in the laboratory. Tests performed between 24-40 psi in the Brake Suspension Test Device developed by Bayrakçeken et al. (2016) as the tire inflation pressure increased more than the rated pressure of 34 psi, it was observed that the pitching force increased as the dynamic wheel radius also increased (8). However, at tire pressures less than 34 psi, the pitch force increased rather than decreased. Tire, which is a polymer material, can show reactions such as adhesion and adhesion to the contact surface at sub-standard tire inflation pressures. This has led to an increase in pitch force at tire inflation pressures below the rated pressure.

Hybrid Iterative Regression analysis was performed in order to model the change of pitching force occurring during braking according to tire pressure. When the effect of tire inflation pressure on pitching force during braking was examined experimentally, a parabolic change was observed. Therefore, periodic functions given in Eq. (8), (9) and (10) and parabolic functions given in Eq. (11) and (12) are used to model the relationship between tire infla 


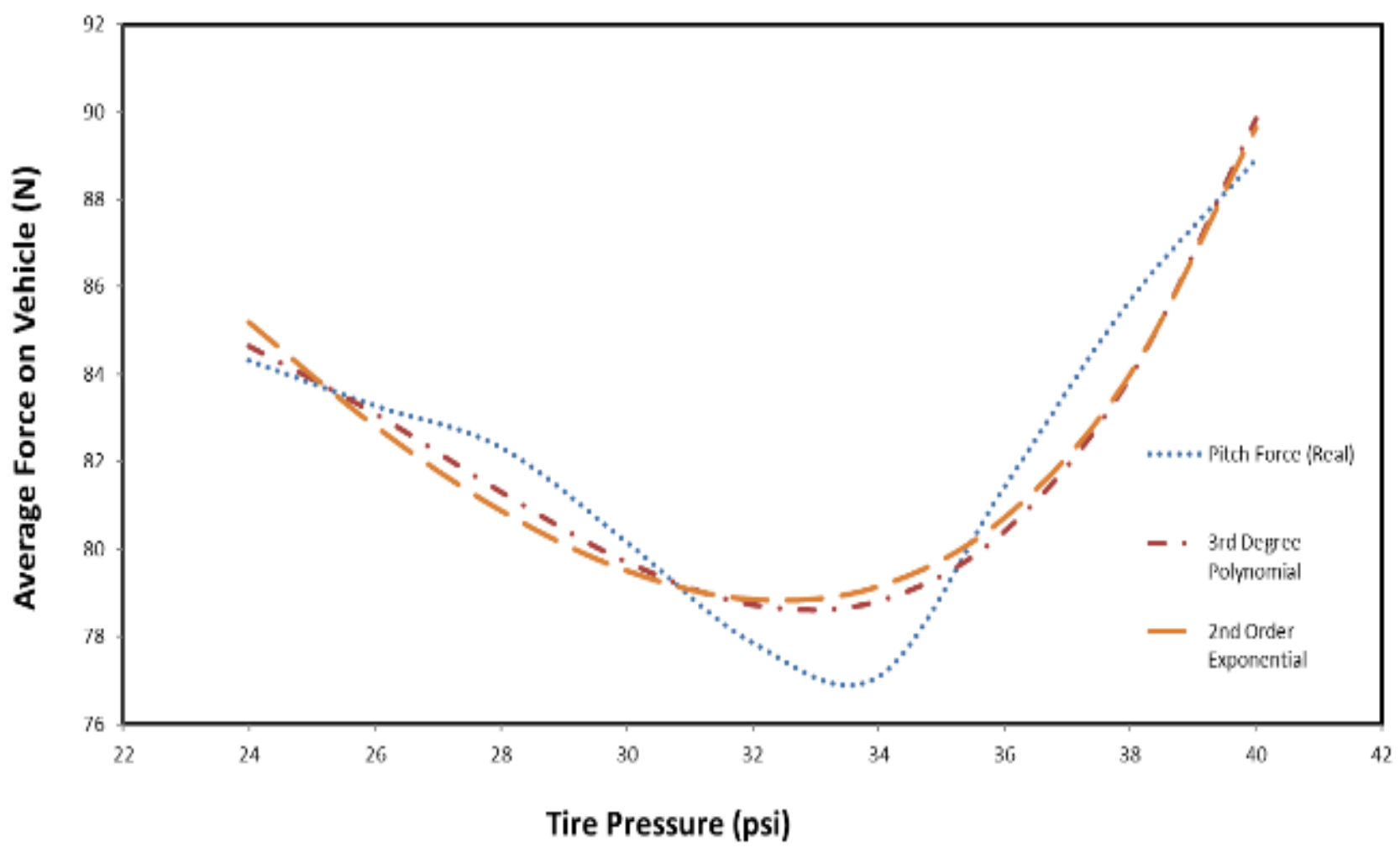

Fig. 5. Mathematical models derived with parabolic functions

-tion pressure and pitching force. When the $\mathrm{R}^{2}$ values of the derived functions are examined, it is seen that the periodic functions provide higher correlations. However, it is evaluated that periodic functions can only provide high correlation over a period of time. As a result, although the correlation coefficients are lower than the periodic functions, it has been determined that parabolic functions are more suitable for modeling the problem addressed in the whole state space globally. Therefore, it has been demonstrated that periodic functions can be used in modeling for local situations where high precision is required. However, it has been observed that parabolic functions are more suitable to make a more general modeling for the problem under consideration. In addition, it has been revealed that the Hybrid Iterative Algorithm, which uses high $\mathrm{R}^{2}$ values obtained as a result of the performed models, has achieved success in curve fitting studies.

Bayrakçeken et al. (2019) was handled only the low tire pressure [7]. In this paper it's investigated the effect of high pressure in addition to low tire pressure, unlike to previous study. Furthermore, it's used five different mathematical models for curve fitting. It was seen that two mathematical models (Fourier Expan-sion and $3^{\text {rd }}$ degree Polynomial) developed by Bayrakçeken et al. (2019) for low tire pressure are also valid for high tire pressure [7]. This situation shows that the obtained empirical formulas are suitable for the physics of discussed problem.

\section{Conflict of Interest Statement}

The authors declare that there is no conflict of interest.

\section{CRediT Author Statement}

Hüseyin Bayrakçeken: Experiment design, Zekeriya Girgin: Creation of non-linear regression equations, Faruk Emre Aysal: Solution of non-linear regression equations, Mustafa Babagiray: Writing the article

\section{Nomenclature}

$a, \mathrm{~b}$, and $\mathrm{c}$ : coefficients of functions

$F_{\text {pitching }} \quad$ : pitching force $(\mathrm{N})$

Frake : braking force $(\mathrm{N})$

$L_{\text {disc }} \quad:$ disc length (m)

$r_{\text {disc }} \quad:$ disc radius $(\mathrm{m})$

$R_{d y n} \quad:$ wheel radius (m)

$\mathrm{R}^{2} \quad$ : coefficient of determination

\section{References}

[1] Bayrakçeken, H. Motorlu taşıtlarda fren performans analizi ve geliştirilen test cihazında uygulanması. Gazi University, PhD Thesis.2002. Ankara, Turkey 
[2] Reiter, M. And Wagner, J. Automated automotive tire inflation system - effect of tire pressure on vehicle handling. 6th IFAC Symposium Advances in Automotive Control. 2010; 12-14.

[3] Koca, A. Lastik hava basıncı ve taşıt hızının dinamik yarıçap değişimine etkilerinin deneysel olarak incelenmesi. Gazi Üniversitesi. Mühendislik ve Mimarlık Fakültesi Dergisi. 2007; 22, 305-311.

[4] Sina, N., Nasiri, S., Karkhaneh, V. Effects of resistive loads and tire inflation pressure on tire power losses and $\mathrm{CO} 2$ emissions in realworld conditions. Applied Energy.2015; 157, 974-983.

[5] Cuong, D.M., Zhu, S., Zhu, Y. Effects of tire inflation pressure and forward speed on vibration of an unsuspended tractor. Journal of Terramechanics. 2013; 50, 185-198.

[6] Karakuş, M., Çolakoğlu, M. Araba lastiğinin farklı basınçlar altında 2 ve 3 boyutlu gerilme analizi. Teknoloji. 2008; 11, 145-151.

[7] Bayrakçeken H., Girgin Z., Aysal F. E., Babagiray M. Nonlineer İteratif Regresyon Analizi Kullanılarak Düşük Lastik Şişirme Basıncinın Yunuslama Kuvvetine Etkisinin İncelenmesi. Afyon Kocatepe University Journal of Science and Engineering. 2019; 19, 490-495.

[8] Bayrakçeken, H., Aysal, F.E., Mutlu, İ. Fren Süspansiyon Test Cihazı Tasarımı ve İmalatı. Afyon Kocatepe University Journal of Science and Engineering. 2016; 16, 454-460

[9] Legendre, A. M. Nouvelles méthodes pour la détermination des orbites des comètes. F. Didot, 1805; 68.

[10]Gauss, C. F. Theoria motus corporum coelestium in sectionibus conicis solem ambientium, 7. Cambridge University Press. 1809; 125151.

[11]Galton, F. Typical laws of heredity. Proceedings of the Royal Institution. $1877 ; 8,282-301$.

[12]Pearson, K. The law of ancestral heredity. Biometrika. 1903; 2, 211228.

[13]Yule, G. U. On the theory of correlation. Journal of the Royal Statistical Society. 1897; 60, 812-854.

[14]Fisher, R. A. The goodness of fit of regression formulae, and the distribution of regression coefficients. Journal of the Royal Statistical Society. 1922; 85, 597-612.

[15]Anscombe F. J. Graphs in Statistical Analysis. The American Statistician. 1973; 27, 17-21. 